FACULDADE DE CIÊNCIAS ECONÔMICAS DA UFRGS
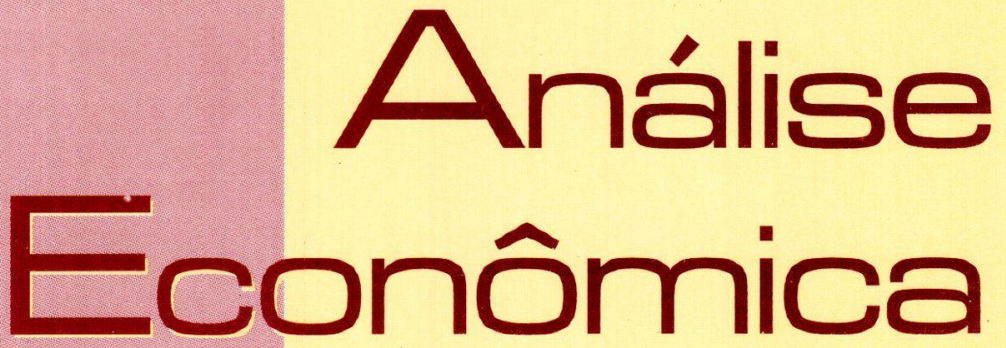

AS LOCOMOTIVAS ENFERRUIADAS

DO CAPITALISMO

Reinaldo Gonçalves

EFICIENNCIA, DESRECULAMENTACC̃O

FINANCEIRA E CRESCIMENTO

ECONOMICO: UMA ABORDAGEM

PÓS-KEYNESIANA

ROGÉRIO SOBREIRA

MERCADOS CONTESTÁVEIS E

COMPEIIÇÃO NO NOVO MODELO

DO SETOR ELÉtRICO BRASILEIRO

ELBIA VINHAES

EDVALDO SANTANa

MICROCRÉDITO: ASPECTOS TEÓRICOS

E EXPERIÊNCIAS

Márcio BobiK Braga

RUDINEI TONETO JR.

A RelaÇão Entre a Política e A ECONOMIA: SUAS IMPLICAÇÓES NO SISTEMA FINANCEIRO

JORGe PESSOA De MENDONĢA

AS RAiZzes CONCEITUAIS DO

INERCIALISMO

VAIDIR RAMAIHO

AUGE E INICIO DO DECLINIIO DA ECONOMIA ARGENTINA

maria Heló́sa lenz

$$
\text { ANO } \begin{array}{r}
18 \\
\text { No } 33
\end{array}
$$

MARÇO, 2000 
Universidade Federal do Rro Grande do Sui

Reitora: Prof ${ }^{a}$. Wrana Maria Panizzi

Faculdade de Ciências Econômicas

Diretora: Prof ${ }^{a}$ Otilia Beatriz Kroeff Carrion

Centro de Estudos e Pesquisas Econômicas

Diretor: Prof. Fernando Ferrari Filho

Departamento de Ciênctás Econòmicas

Chefe: Prof Luiz Alberto Oliveira Ribeiro de Miranda

Curso de Pós-Graduação em Economia

Coordenador: Prof. Marcelo Savino Portugal

Curso de Pós-Graduação em Economia Rural

Coordenador: Prof. Carlos Guilherme A. Mielitz Netto

Consel.ho Editorial:

Achyles B. Costa, Aray M. Feldens, Carlos A. Crusius, Carlos G. A. Mielitz Netto, Eduardo A. Maldonado Filho, Eduardo P. Ribeiro, Eugênio Lagemann, Fernando Ferrari Filho, Gentil Corazza, Marcelo S. Portugal, Nali I. Souza, Otnia B. K Carrion, Paulo A. Spohr, Paulo D. Waquil, Pedro C. D. Fonseca, Roberto C Moraes, Ronald Otto Hillbrecht, Stefano

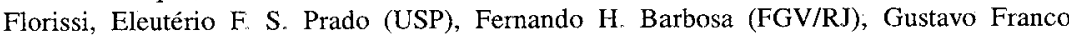
(PUC/RJ), João R. Sanson (UFSC), Joaquim P. Andrade (UnB), Juan H. Moldau (USP), Paul Davidson (Univ. of Tennessee), Werner Baer (Univ. of Illinois).

\section{Comissāo Entrorial:}

Eduardo Augusto Maldonado Filho, Fernando Ferrari Filho, Gentil Corazza, Marcelo Savino Portugal, Paulo Dabdab Waquil; Roberto Camps Moraes.

EorTor: Gentil Corazza

Edrror Adjunto: Pedro Silveira Bandeira

Secretário: Márcio Souza de Vargas

Revisão de Textos: Vanete Ricacheski

Fundador: Prof Antônio Carlos Santos Rosa

Os materiais publicados na revista Análise Econômica são da exclusiva responsabilidade dos autores. É permitida a reprodução total ou parcial dos trabalhos, desde que seja citada a fonte Aceita-se permuta com revistas congêneres. Aceitam-se, também, livros para divulgação, elaboração de resenhas e recensões. Toda correspondência, material para publicação (vide normas na terceira capa), assinaturas e permutas devem ser dirigidos ao seguinte destinatário:

PROF GENTIL CORAZZA

Revista Análise Econômica - Av. João Pessoa, 52

CEP 90040-000 PORTO ALEGRE - RS, BRASIL.

Telefones: (051) 316-3348 e 316-3440 - Fax: (051) 316-3990

E-mail: rae@vortex.ufrgs.br

Análise Econômica

Ano 18, $\mathrm{n}^{\circ} 33$, março, 2000 - Porto Alegre

Faculdade de Ciências Econômicas, UFRGS, 2000

Periodicidade semestral, março e setembro

1. Teoria Econômica - Desenvolvimento Regional -

Economia Agrícola - Pesquisa Teórica e Aplicada -

Periódicos. I. Brasil.

Faculdade de Ciências Econômicas,

Universidade Federal do Rio Grande do Sul. 


\title{
As locomotivas enferrujadas do capitalismo
}

\author{
Reinaldo Gonçalves*
}

\begin{abstract}
Resumo: Ao longo do século XX o capitalismo mostrou-se um sistema altamente instável. Os sinais de senilidade do sistema tornaram-se cada vez mais evidentes na medida em que se aproximava a virada do século XX para o século XXI. Para enfrentar a trajetória marcadamente cíclica do sistema capitalista um conjunto de remédios tem sido aplicado com resultado variável ao longo de mais de um século. Estes "velhos remédios" têm sido usados de forma recorrente e deverão se constituir na base de tratamento do sistema no século XXI. Na era da globalização do último quarto do século XX o sistema econômico capitalista está tendo um desempenho inferior àquele observado em outros ciclos de expansão (1870-1913 e 1950-1973). As perspectivas de longo prazo, que incluiria as primeiras décadas do século XXI, não podem ser vistas com otimismo na medida em que as "locomotivas" de crescimento do sistema parecem estar enferrujadas.
\end{abstract}

Palavras-chave: Capitalismo, economia mundial, crise.

Abstract: In the Twentieth Century Capitalism was a highly volatile system. In the last decades of the century, it became even more evident that the system had signs of senility. A set of strategies has been used to reverse the cyclical behavior the most advanced economies of the world. These "old" mechanisms will also be used in the near future. During the age of globalization the world capitalist system has had an economic performance inferior to that it had in other cycles of expansion (1870-1913 and 19501973). The long run perspectives are not optimistic insofar as the growth engines of the system seem to be rust.

Key-words: Capitalism, world economy, crise.

\section{Introdução}

$\mathrm{Na}$ era da globalização do último quarto do século XX, o sistema econômico capitalista está tendo um desempenho inferior àquele observado em outros ciclos de expansão (1870-1913 e 1950-1973). As perspectivas de longo prazo, que incluiria as primeiras décadas do século XXI, não podem ser vistas com otimismo na medida em que as "locomotivas" de crescimento do sistema parecem estar enferrujadas.

\footnotetext{
* Professor Titular de Economia Internacional da Universidade Federal do Rio de Janeiro.
} 
A ecönomia norte-americana, que funcionou como locomotiva do sistema capitalista no século XX, mostrou sinais evidentes de que estava enferrujada em meados dos anos 70 . Graves problemas nos EUA provocaram a ruptura do Acordo de Bretton Woods, que regulava o sistema monetário internacional centrado no dólar, em 1971. Por outro lado, o "milagre" japonês iniciado nos anos 50 se apresentava como uma opção de nova locomotiva para o sistema econômico mundial. Do início dos anos 70 até o final dos anos 80, a situação era simples: a Europa estava esclerosada (Euroesclerose), a economia dos EUA tinha perdido seu dinamismo e apresentava sinais de senilidade e fortes desequilíbrios (fiscal e de comércio exterior), enquanto o Japão tinha um desempenho espetacular. O resultado era um argumento igualmente simples: o Japão seria a locomotiva capitalista do século XXI. Esta locomotiva seria auxiliada por "vagões" emergentes e potentes, que eram as economias dinâmicas do Sudeste Asiático (Arrighi, 1996).

A tese da nova hegemonia japonesa não se sustentou durante muito tempo. Ao longo dos anos 90, a locomotiva japonesa descarrilou, o mesmo acontecendo com os seus vagões do Sudeste Asiático. Na virada do século XX para o século XXI, não há qualquer cenário plausível de que a economia asiática volte a funcionar, em um horizonte de tempo previsível, com algum efeito locomotiva sobre a economia mundial. Parece haver, se não um consenso, pelo menos uma percepção forte e bastante generalizada neste sentido.

No que se refere aos EUA, o desempenho econômico relativamente favorável durante os anos 90, inclusive, com a eliminação do desequilíbrio do déficit publico, restaurou a hipótese da hegemonia militar com dinamismo económico. De fato, a ruptura do bloco soviético significou uma forte restauração da hegemonia norte-americana ao longo da década de 90 . Ademais, a partir de 1992, a economia dos EUA entrou em um ciclo expansivo, que tem alimentado a hipótese de dinamismo econômico deste país e, portanto, renovou-se a visão quanto ao seu efeito locomotiva em escala global. Esta tende ser a visão predominante tanto no debate nacional como no internacional.

A maioria dos analistas tende, também, a aceitar o fato de que este dinamismo tem provocado um forte processo de exclusão social em escala global. A hipótese defendida pela totalidade dos liberais, pela quase totalidade dos social-democratas e mesmo por parte expressiva dos analistas de esquerda, é que a globalização, sob a hegemonia restaurada dos EUA seria dinâmica e representaria a modernidade do século XXI, ainda que marcada pela forte exclusão social e pela instabilidade financeira. Vale notar que liberais e social-democratas, bem como alguns analistas de esquerda, divergem marginalmente, tanto no que se refere à visão de um capitalismo triun- 
fante, quanto ao escopo de políticas compensatórias para a exclusão social (e.g., gastos educação) e a instabilidade financeira (e.g., Tobin tax).

Este texto apresenta uma visão radicalmente distinta a respeito do capitalismo nesta virada de século, a partir de um conjunto de argumentos principais. O primeiro argumento é que o capitalismo mundial entra no século XXI com suas locomotivas enferrujadas. Este argumento é verdade tanto para a economia japonesa, como para a economia norte-americana. $O$ segundo é que não se descobriram novos remédios para a antiga doença da instabilidade do sistema gerada pelo descompasso entre a capacidade de oferta e de demanda de mercadorias. Os velhos remédios continuarão a ser aplicados no século XXI, sendo que, de modo geral, os remédios estão cada vez menos eficazes. O terceiro argumento é que a velha doença de elevada instabilidade do capitalismo dos séculos XIX e XX deverá contaminar ainda mais o sistema no século XXI, em decorrência do grau de senilidade alcançado pelas principais economias capitalistas do mundo.

Os argumentos acima podem ser resumidos em uma tese principal: o capitalismo entra no século XXI bastante enfraquecido devido à senilidade crescente das economias maduras, as suas locomotivas enferrujadas são incapazes de mover o sistema de forma sustentável e em alta velocidade, e os remédios continuam os mesmos. Neste sentido, é provável que a instabilidade econômica aumente, inclusive, em escala global.

$\mathrm{Na}$ medida em que, no processo de enfrentamento das crises capitalistas, os remédios econômicos (gastos públicos, progresso técnico e internacionalização da produção) tornem-se menos eficazes, ao mesmo tempo em que a saída política (distribuição de riqueza e renda) seja restringida, resta a saída clássica, tão poderosa quanto terrificante: a guerra. $\mathrm{O}$ século $\mathrm{XX}$ foi o mais sangrento da história da humanidade (Hobsbawm, 1997). Não deveremos, entretanto, nos surpreender, caso o século XXI seja ainda mais marcado por conflitos bélicos do que o século XX.

O texto está dividido em cinco seções. Na primeira seção apresentamse alguns dados empíricos sobre o desempenho das principais economias capitalistas durante os séculos XIX e XX. Na segunda seção faz-se uma breve discussão a respeito dos principais saídas encontradas pelo capitalismo no século XX para enfrentar seu problema de instabilidade crônica causada, fundamentalmente, pelo descompasso entre capacidade de oferta $\mathrm{e}$ de demanda de mercadorias. Discute-se a eficácia relativa destas saídas ou remédios para as crises do capitalismo. Estes remédios são gastos públicos (remédio keynesiano); inovação tecnológica (remédio schumpeteriano); distribuição de riqueza e renda (saída política); demanda externa (imperialismo e globalização); e, guerras (alto, médio e baixo impactos). 
$\mathrm{Na}$ terceira seção analisam-se as causas da principal crise do capitalismo no século XX - a crise econômica dos EUA que eclodiu em 1929 - e os remédios usados no contexto do New Deal. O argumento central é que as políticas tipicamente de proteção e reforma do sistema, por meio da expansão do consumo e do investimento, foram incapazes de recolocar a locomotiva e o "trem" da economia mundial nos trilhos. A Segunda Guerra Mundial foi a "tábua de salvação" do sistema.

As seções seguintes tratam do "descarrilamento" das locomotivas do capitalismo nesta virada de século. A quarta seção examina o descarrilamento da economia japonesa durante os anos 90 . O principal argumento é que o Japão tornou-se uma economia capitalista madura, com seus beneficios e seus custos. Isto significa que o Japão está sofrendo da síndrome de insuficiência de demanda agregada e, portanto, não tem força suficiente para se mover de forma sustentável e em alta velocidade. São os sinais da síndrome da senilidade e da instabilidade. Neste sentido, a economia japonesa deixou de ser o que não foi: a locomotiva do sistema econômico mundial. A hegemonia japonesa é natimorta.

Na quinta seção volta-se a examinar a economia norte-americana, só que na última década do século XX. O principal argumento é que o combustível que está movendo a locomotiva norte-americana, a partir de 1992, é o mesmo usado nos anos 20 (valorização financeira). $O$ argumento prossegue no sentido de que este combustível não pode durar indefinidamente. Em algum momento do futuro próximo, a marcha forçada pelo impulso financeiro, deverá provocar fissuras na economia norte-americana.

$\mathrm{Na}$ última seção faz-se um sumário dos principais resultados da análise, bem como algumas considerações gerais sobre a evolução do sistema econômico mundial no início do século XXI.

\section{Desempenho de longo prazo}

No último quarto do século XX, as principais economias capitalistas maduras estão tendo um desempenho inferior àquele dos ciclos de expansão nos períodos 1870-1913 e 1950-1973. A evidência mostra que, de um modo geral, as principais economias capitalistas (Estados Unidos, Grã-Bretanha, Japão, França e Alemanha) têm uma taxa de crescimento médio anual do PIB real no período 1973-2000 inferior às taxas dos períodos 1870-1913 e 1950-1973 (Tabela 1). O menor dinamismo é particularmente evidente no caso dos EUA - locomotiva capitalista do século XX, cuja taxa média anual de crescimento do PIB tem mostrado uma clara tendência de redução secular. Esta taxa reduziu-se de 3,9\% em 1870-1913 para 3,6\% em 1950-1973 e 
Tabela 1. Taxa de crescimento do PIB real: Principais economias capitalistas, séculos XIX e $\mathrm{XX}$

\begin{tabular}{lcccccc}
\hline \multicolumn{1}{c}{ País/ Período } & $1820-1870$ & $1870-1913$ & $1913-1950$ & $1950-1973$ & $1973-2000$ & $1820-2000$ \\
\hline Estados Unidos & 4,5 & 3,9 & 2,8 & 3,6 & 2,6 & 3,6 \\
Grã-Bretanha & 2,0 & 1,9 & 1,3 & 3,0 & 1,9 & 2,0 \\
Japão & 0,3 & 2,3 & 2,2 & 9,3 & 3,0 & 2,7 \\
França & 1,2 & 1,5 & 1,1 & 5,0 & 2,1 & 1,9 \\
Alemanha & 1,6 & 2,8 & 1,3 & 5,9 & 2,2 & 2,5 \\
Média & 2,4 & 2,5 & 2,0 & 4,9 & 2,5 & 2,7 \\
\hline
\end{tabular}

Fontes e Notas: Elaboração de Reinaldo Gonçalves com base em dados de Angus Maddison, Dynamic Forces in Capitalist Development. A Long-run Comparative View, Oxford University Press, 1991, p. 50; e IMF, World Economic Outlook, Washington D.C., International Monetary Fund, October, p. 172. Dados para 1999-2000 referem-se a projeções. A média para cada período entre 1820 e 1973 refere-se à média aritmética das taxas das 16 principais economias capitalistas avançadas. A média para o período 1973-2000 refere à taxa média ponderada para 28 economias capitalistas avançadas.

para 2,6\% em 1973-2000. A situação do Japão é particularmente interessante na medida em que a taxa de crescimento de longo prazo reduziu-se dramaticamente de 9,3\% em 1950-1973 para 3,0\% em 1973-2000.

Quando se leva em conta o crescimento per capita da renda (Tabela 2), a evidência é no sentido de um menor dinamismo, principalmente em comparação com o período pós-Segunda Guerra. Entretanto, no que se refere aos Estados Unidos, a taxa de crescimento de longo prazo da renda per capita na era da globalização é historicamente a menor, somente comparável a do período 1820-1870. A taxa de crescimento da renda per capita nos EUA é de 1,5\% em 1973-2000, inferior às taxas de 1,8\% em 1870-1913 e $2,2 \%$ em 1950-1973. Ademais, a taxa de crescimento da renda per capita dos EUA na era da globalização é inferior à taxa de crescimento de $1,6 \%$ no difícil período 1913-1950, entre as duas grandes guerras mundiais.

$\mathrm{Na}$ era da globalização, o destaque de desempenho fica por conta das exportações. Deve-se notar, entretanto, que a evidência empírica (Tabela 3) mostra taxas de crescimento real das exportações em 1973-2000, de modo geral, inferiores às taxas do período 1950-1973. É bem verdade que a relação entre taxa de crescimento das exportações e taxa de crescimento da renda aumentou na era da globalização (Tabela 4).

A relação média aumentou de 1,75 para 2,04 entre os períodos 1950 1973 e 1973-2000. Neste ponto é interessante observar que, para as principais economias capitalistas maduras, estas relações giram em torno de 2 , isto é, o crescimento anual da renda nacional de $2 \%$ está associado a um crescimento anual da exportação de $4 \%$. 
Tabèla 2. Taxa de crescimento do PIB real per capita: Principais economias capitalistas, séculos XIX e XX

\begin{tabular}{lcccccc}
\hline \multicolumn{1}{c}{ País/Período } & $1820-1870$ & $1870-1913$ & $1913-1950$ & $1950-1973$ & $1973-2000$ & $1820-2000$ \\
\hline Estados Unidos & 1,5 & 1,8 & 1,6 & 2,2 & 1,5 & 1,7 \\
Grã-Bretanha & 1,2 & 1,0 & 0,8 & 2,5 & 1,6 & 1,3 \\
Japão & 0,1 & 1,4 & 0,9 & 8,0 & 2,4 & 1,9 \\
França & 0,8 & 1,3 & 1,1 & 4,0 & 1,7 & 1,5 \\
Alemanha & 0,7 & 1,6 & 0,7 & 4,9 & 2,0 & 1,6 \\
Média & 0,9 & 1,4 & 1,2 & 3,8 & 1,9 & 1,6 \\
\hline
\end{tabular}

Fontes e Notas: Elaboração de Reinaldo Gonçalves com base em dados de Angus Maddison, Dynamic Forces in Capitalist Development. A Long-run Comparative View, Oxford University Press, 1991, p. 49 e IMF, World Economic Outlook, Washington D.C., International Monetary Fund, October, p. 176. Dados para 1999-2000 referem-se a projeções. A média para cada período entre 1820 e 1973 refere-se à média aritmética das taxas das 16 principais economias capitalistas avançadas. A média para o período 1973-2000 refere à taxa média ponderada para 28 economias capitalistas avançadas.

Tabela 3. Taxa de crescimento do volume das exportações: Principais economias capitalistas, séculos XIX e XX

\begin{tabular}{lcccccc}
\hline \multicolumn{1}{c}{ País/Período } & $1820-1870$ & $1870-1913$ & $1913-1950$ & $1950-1973$ & $1973-2000$ & $1820-2000$ \\
\hline Estados Unidos & 4,7 & 4,9 & 2,2 & 6,3 & 5,3 & 4,5 \\
Grã-Bretanha & 4,9 & 2,8 & 0,0 & 3,9 & 3,9 & 3,7 \\
Japão & nd & 8,5 & 2,0 & 15,4 & 6,2 & 8,2 \\
França & 4,0 & 2,8 & 1,1 & 8,2 & 4,6 & 4,6 \\
Alemanha & 4,8 & 4,1 & $-2,8$ & 12,4 & 4,9 & 4,8 \\
Média & 4,2 & 3,9 & 1,0 & 8,6 & 5,1 & 4,1 \\
\hline
\end{tabular}

Fontes e Notas: Elaboração de Reinaldo Gonçalves com base em dados de Angus Maddison, Dynamic Forces in Capitalist Development. A Long-run Comparative View, Oxford University Press, 1991, p. 75 e IMF, World Economic Outlook, Washington D.C., International Monetary Fund, October, p. 202. Dados para 1999-2000 referem-se a projeções. A média para cada período entre 1820 e 1973 refere-se à média aritmética das taxas das 16 principais economias capitalistas avançadas. A média para o período 1973-2000 refere à taxa média ponderada para 28 economias capitalistas avançadas. (nd) não disponível.

Do ponto de vista empírico deve-se destacar ainda que houve uma redução significativa da taxa de crescimento do produto potencial dos países desenvolvidos entre as décadas de 60-70 e 80-90. No caso dos Estados Unidos, a taxa média anual do crescimento do produto potencial reduziu-se de $3,8 \%$ na década de 60 para $2,3 \%$ no período $1990-94$. No caso da Alemanha, a queda correspondente foi de $4,1 \%$ para $2,7 \%$, enquanto no Japão a redução foi de $8,8 \%$ para $3,3 \%$ (UNCTAD, 1995, p. 171-173). Ademais, a 
Tabela 4. Relação entre a taxa de crescimento do volume das exportações e a taxa de crescimento do PIB real: Principais economias capitalistas, séculos XIX e XX

\begin{tabular}{lcccccc}
\hline \multicolumn{1}{c}{ País/Período } & $1820-1870$ & $1870-1913$ & $1913-1950$ & $1950-1973$ & $1973-2000$ & $1820-2000$ \\
\hline Estados Unidos & 1.04 & 1.26 & 0.78 & 1.75 & 2.03 & 1.25 \\
Grã-Bretanha & 2.45 & 1.47 & 0.00 & 1.30 & 2.05 & 1.85 \\
Japão & nd & 3.69 & 0.91 & 1.65 & 2.06 & 3.03 \\
França & 3.33 & 1.86 & 1.00 & 1.64 & 2.19 & 2.42 \\
Alemanha & 3.00 & 1.46 & -2.15 & 2.10 & 2.22 & 1.92 \\
Média & 1.75 & 1.56 & 0.50 & 1.75 & 2.04 & 1.52 \\
\hline
\end{tabular}

Fontes e Notas: Elaboração de Reinaldo Gonçalves com base em dados de Angus Maddison, Dynamic Forces in Capitalist Development. A Long-run Comparative View, Oxford University Press, 1991, p. 49 e p. 75 e IMF, World Economic Outlook, Washington D.C., International Monetary Fund, October, p. 176 e p. 202. Dados para 1999-2000 referem-se a projeções. (nd) não disponível. A média para cada periodo entre 1820 e 1973 refere-se à média aritmética das taxas das 16 principais economias capitalistas avançadas. A média para o período 1973-2000 refere à taxa média ponderada para 28 economias capitalistas avançadas.

taxa média anual de crescimento da formação bruta de capital fixo nos Estados Unidos caiu de 5,0\% no período $1960-68$ para $2,5 \%$ no período 1979-90. No caso da Alemanha, a queda correspondente foi de 3,1\% para $1,9 \%$ e, no caso do Japão, a redução foi $15,2 \%$ para $5,0 \%$ nos períodos mencionados. O resultado foi um processo generalizado de desaceleração do crescimento econômico das economias capitalistas na era da globalização. De fato, estas economias parecem estar convergindo para um nível medíocre da ordem de $2 \%$ para o crescimento anual do PIB.

Naturalmente, deve-se evitar argumentos deterministas a respeito da "fase terminal" do capitalismo. O fato a destacar é que o desempenho futuro do capitalismo vai depender da evolução da senilidade do sistema, da gravidade do descarrilamento das locomotivas, bem como do "coquetel" de remédios, suas dosagens e efícácia. Todavia, a irracionalidade econômica e a injustiça social continuarão como as marcas indeléveis do sistema capitalista no século XXI.

\section{Crises capitalistas: velhos remédios}

Economias capitalistas maduras defrontam-se com cinco saídas básicas ou remédios para crises de acumulação. O primeiro é o conhecido "remédio keynesiano", com políticas fiscais expansionistas e déficits públicos. A expansão dos investimentos públicos é uma das principais formas de se realizar esta saída para a crise. Entretanto, esta saída tem retornos decrescentes 
na medida em que os déficits públicos recorrentes provocam o crescimento da dívida pública interna e acabam gerando políticas monetárias restritivas. A experiência do Japão nos anos 90 é o melhor exemplo contemporâneo das limitações da via keynesiana.

A segunda saída é o "remédio schumpeteriano" de indução do processo de destruição criadora, por meio do qual se promove uma nova onda de inovações tecnológicas e organizacionais capaz de aumentar os gastos (consumo e investimento). Entretanto, do ponto de vista da demanda agregada, pode ocorrer que este processo destrua mais do que crie, quando, por exemplo, as inovações tecnológicas e organizacionais têm um forte componente poupador de mão-de-obra e, ceteris paribus, acabem reduzindo a massa de salários na economia. Desta forma, trava-se o conhecido "mecanismo do acelerador", por meio do qual o maior crescimento da demanda provoca aumento dos investimentos. Ademais, o problema com este processo é que ele tem um forte componente aleatório (invenções, inovações e decisões de investimento), mesmo no caso de países que têm uma forte institucionalidade articulando governo e empresas, política industrial e tecnológica e investimento privado.

$O$ terceiro remédio é a distribuição de renda e riqueza. Ainda que esta resposta seja muito mais efetiva em economias atrasadas, com populações pobres e enormes desigualdades, ela pode ter algum impacto nas economias maduras. $\mathrm{O}$ estado de bem-estar social desenvolvido, principalmente pelos social-democratas na Europa no pós-Segunda Guerra Mundial, é um exemplo paradigmático. Projetos socialistas tendem, naturalmente, a se ancorar nesta via para realizar transformações estruturais. O problema central é de natureza política.

O quarto remédio encontra-se no front externo e procura transformar as exportações na locomotiva da economia nacional. Neste sentido, as economias avançadas devem procurar alcançar uma trajetória de crescente competitividade internacional. A maior dificuldade é que, no contexto internacional atual, há crescente dificuldade para este tipo de estratégia, pois a maioria dos países procura explorá-la no limite. Restrições pelo lado da demanda também são cada vez maiores, tendo em vista o lento crescimento da economia mundial, suas flutuações cíclicas e as ondas de protecionismo.

O quinto e último remédio é a guerra. Este remédio também pode ser aplicado em doses homeopáticas (exemplos: Coréia nos anos 50, Vietnam nos anos 60, Oriente Médio nos anos 70, "guerra nas estrelas" nos anos 80, guerra no Golfo no início dos anos 90 e nos Balcãs no final dos anos 90). $\mathrm{O}$ tratamento alopático corresponde aos conflitos de alto impacto: Primeira e Segunda Guerras Mundiais, bem como a Guerra Fria. 
Desde o início dos anos 80 , a saída preferencial, usada pelas economias maduras capitalistas, tem sido aquela que procura maior acesso aos mercados internacionais de bens, serviços e capitais. Esta estratégia surge como reação à insuficiência de demanda agregada interna nos países capitalistas maduros, sendo ativamente promovida por governos e empresas transnacionais, e, portanto, constitui-se no mais importante determinante do fenômeno da globalização econômica deste final de século (Gonçalves, 1999).

\section{Crise de 29, New Deal e Guerra}

No século XX, a crise econômica mais grave dos países capitalistas ocorreu no período 1929-39. O epicentro desta crise foi os Estados Unidos. Entre 1929 e 1932, a renda norte-americana caiu 38\% e a taxa de desemprego saltou de $3 \%$ para $24 \%$. A crise econômica norte-americana atingiu, uma após outra, todas a principais economias capitalistas. A depressão que se iniciou em 1929 teve origem no excesso de capacidade de produção, e o seu principal detonador foi a brutal queda dos preços dos produtos agrícolas. A explosão da bolha especulativa de crédito e de aplicações em bolsa (o grande crash da bolsa de valores de Nova York em 1929), a falência dos bancos e o elevado nível de endividamento das empresas e dos indivíduos foram fatores importantes, mas não foram os determinantes primários da espiral de queda de produção, renda e preços.

O governo republicano de Hoover, aferrado ao liberalismo econômico, foi incapaz de interromper o processo de depressão. Em março de 1933, o democrata Franklin Roosevelt tomou posse e iniciou a implementação de um conjunto de medidas que ficaram conhecidas como New Deal. As principais políticas foram implementadas em 1933, e reforçadas em 1935 e 1938. O objetivo central era interromper e reverter o processo de crise econômica. As medidas foram orientadas para aumentar o consumo e o investimento, bem como reduzir o custo social da crise. O principal instrumento foi a intervenção e regulação estatal. $\mathrm{O}$ New Deal representou o desmoronamento do liberalismo econômico.

As medidas usadas abrangeram as esferas monetária, financeira, agrícola, industrial e social. Na esfera monetária e financeira, as principais políticas procuravam evitar uma crise sistêmica, principalmente, do setor bancário. Houve ruptura com o sistema do padrão-ouro (mudança da paridade fixa ouro-dólar e proibição da exportação de ouro), maxidesvalorização do dólar (41\%), imposição de controles de câmbio, e maior regulamentação do sistema financeiro. 
A política de expansão do consumo e do investimento ("o remédio keynesiano") esteve centrada nos gastos públicos, por meio do incremento da oferta monetária, com a realização de grandes obras públicas e programas de ajuda aos desempregados. No setor agrícola, a política envolveu a compra de estoques, subsídios à redução da produção e incentivos às exportações. No setor industrial, o governo promoveu acordos setoriais com o intuito de retomada da produção e aumento da massa de salários. Este último objetivo baseava-se em acordos coletivos orientados para a limitação das horas trabalhadas e a definição de pisos salariais.

Houve, também, a elevação das barreiras de proteção contra as importações e o controle de preços, bem como o reforço dos mecanismos antitrustes. Medidas adicionais foram introduzidas em 1935 e 1938 com o objetivo de aumentar o poder de barganha da classe trabalhadora como, por exemplo, convenções coletivas, direito de greve, legalidade das associações sindicais, restrições ao trabalho infantil, estabelecimento do salário mínimo e regime de 40 horas semanais. Na esfera social, houve a expansão do sistema de seguro desemprego, bem como a ampliação do direito de aposentadoria.

As medidas de Roosevelt representaram mudanças conjunturais e estruturais importantes nos EUA. Entretanto, ainda que o New Deal tenha sido bem-sucedido no sentido de frear a depressão econômica e reduzir os seus custos, ele fracassou no sentido de reverter a crise. Por exemplo, o número de desempregados, que havia sido de 12 milhões no auge da crise em 1933, ainda era muito elevado em 1939 (8 milhões). Entre 1929 e 1939, o nível de produção industrial manteve-se praticamente o mesmo e a renda real caiu.

As políticas de Roosevelt não afetaram o sistema de propriedade dos meios de produção ou mesmo a estrutura de distribuição de riqueza. Ademais, não houve esforço algum de planejamento econômico ou planificação. É evidente que o New Deal não teve qualquer paralelo com o socialismo. Não há dúvida de que houve mudanças institucionais importantes promovidas pelas políticas regulatórias e intervencionistas. Todavia, estas mudanças representaram unicamente a reforma do sistema. A classe dirigente dos EUA foi levada a promover um experimento reformista com o intuito de resgatar o capitalismo norte-americano, que afundava em uma grave crise econômica e social.

$\mathrm{O}$ New Deal representou um freio à trajetória de crise econômica e amorteceu os impactos sociais e políticos da crise. O seu principal atributo foi o desmoronamento do liberalismo econômico. Sua principal consequiência foi evitar a ruptura das instituições políticas. A grande lição do New Deal é esta: o capitalismo precisa restringir o liberalismo econômico para manter a estabilidade política e as instituições democráticas. 
Em 1939 o New Deal terminou, sem reverter a crise. Mas, neste ano, entrou em ação um poderoso mecanismo de resgate do sistema econômico dos EUA, que reverteu a crise de forma tão espetacular quanto terrificante. Este mecanismo foi a Segunda Guerra Mundial que, a partir de setembro de 1939, funcionou como importante fonte de expansão da demanda externa por produtos e equipamentos norte-americanos. $O$ resgate se completou quando os EUA entraram na guerra em novembro de 1941.

De fato, as medidas de Roosevelt não foram capazes de reverter a trajetória de crise sistêmica. Ao fim e ao cabo, foi feita uma operação de resgate. O New Deal não passou de um "bote salva-vidas" de um sistema, que precisou ser resgatado pelos porta-aviões da Segunda Guerra Mundial.

\section{A crise de acumulação e o descarrilamento da economia japonesa: a locomotiva que não passou de vagão}

A economia japonesa descarrilou nos anos 90 . Não há cenário plausível de que voltará para os trilhos tão cedo. Parece ainda menos provável que se tornará uma locomotiva do sistema econômico mundial.

A economia japonesa entrou em uma trajetória de instabilidade e crise em 1992, e que persiste na virada do século. As perspectivas são pouco otimistas quanto ao futuro próximo, tanto no curto como no médio prazo (The Economist, 2 de janeiro de 1999, p. 61). No período 1992-98, o Japão apresentou um desempenho altamente decepcionante na medida em que, neste período, o crescimento acumulado da renda foi de $5,4 \%$, isto é, a taxa média anual de crescimento do PIB japonês foi de $0,8 \%$. As projeções "otimistas" para 1999-2000 significariam um desempenho da ordem de $0,7 \%$ de crescimento médio anual do PIB no período $1992-2000$, isto é, um crescimento da renda per capita de $0,5 \%$ anual.

A dramaticidade da atual situação econômica do Japão pode ser vista em termos do seu desempenho histórico. Na época dourada do capitalismo no pós-Segunda Guerra Mundial, o milagre japonês manifestou-se com taxas de crescimento do PIB per capita de $10 \%$ anuais. Na realidade, o Japão foi o único país capitalista com taxa de crescimento média anual da renda per capita maior do que 6\% no período 1950-70. A renda per capita no Japão dobrava a cada sete anos. Nos anos de crise econômica mundial ao longo dos anos 70, a economia japonesa teve o melhor desempenho entre todas a economias capitalistas avançadas, com um crescimento médio anual da renda per capita de 4,9\%, significativamente mais elevada do que a dos Estados Unidos (Van Der Wee, 1984, p. 36). Assim, enquanto o Japão tinha um crescimento médio anual do PIB de $4,0 \%$ no período de auge da crise 
em 1974-82, os Estados Unidos e a Alemanha Ocidental cresciam 1,5\% e $1,6 \%$, respectivamente.

Ainda que tenha havido um menor dinamismo econômico nos anos 70 e 80 , comparativamente às duas décadas posteriores à Segunda Grande Guerra, o fato é que o processo de ajuste da economia japonesa foi extraordinário, segundo qualquer tipo de avaliação. Houve uma restruturação produtiva extraordinária e um aumento significativo da competitividade internacional do Japão, que começou a enfrentar crescentes barreiras comerciais no mercado internacional. Para ilustrar, o coeficiente exportação/PIB do Japão cresceu de 11\% em 1979 para 15\% em 1985 (Brenner, 1998, p. 235).

Os momentos, talvez, mais marcantes da história econômica contemporânea do Japão foram o Acordo Plaza de 1985 e o Acordo Louvre de 1987. Nestes acordos, os países desenvolvidos acertaram mecanismos de intervenção no sistema monetário internacional e, mais precisamente, no mercado de câmbio, no sentido da depreciação do dólar com relação às moedas européias e, principalmente, ao iene japonês.

Para fazer face às crescentes pressões internacionais a partir de 1985, o Japão fez outro significativo ajuste estrutural orientado não somente para 0 aumento da competitividade internacional, mas também no sentido de reorientar a expansão da renda para o mercado interno. Investimentos em infra-estrutura econômica e social envolveram taxas elevadas de investimento e, portanto, de crescimento da renda. A política fiscal expansionista foi acompanhada por uma política monetária igualmente frouxa. O resultado no período 1986-89, pelo lado real da economia, foi crescimentos de $10,5 \%$ do investimento agregado, $6,7 \%$ do estoque de capital industrial e $4,8 \%$ do $\mathrm{PIB}$, anuais. Os investimentos em pesquisa e desenvolvimento tecnológico e a produtividade também cresceram significativamente. Na segunda metade dos anos 80, as exportações japonesas reorientaram-se, em grande medida, para a Europa, cuja participação no valor das exportações do Japão cresceu de $13 \%$ em 1985 para $22 \%$ em 1990, mais do que compensando a perda de participação relativa do mercado norte-americano (de $40 \%$ para $32 \%$ no período).

A restruturação produtiva foi acompanhada, também, por um deslocamento para cima na escala de vantagens comparativas do Japão. O upgrade das exportações japonesas esteve associado a um deslocamento da produção de bens mais intensivos em mão-de-obra e capital para os países do Sudeste Asiático (principalmente, Tailândia, Coréia do Sul, Malásia, Filipinas e Indonésia). Este deslocamento envolveu um aumento expressivo do investimento externo direto, bem como mudanças na composição dos fluxos de comércio exterior, do Japão. 
O ajuste japonês provocou um aumento do investimento externo direto na direção dos países do Sudeste Asiático, com base em uma estratégia de divisão intra-regional do trabalho. Ademais, os investimentos externos japoneses aumentaram significativamente no resto do mundo, inclusive, na Europa e nos Estados Unidos. O investimento externo direto representou, de fato, uma forma alternativa de internacionalização da produção japonesa, tendo em vista o protecionismo crescente nos países desenvolvidos. O Japão tornou-se, então, o mais importante país investidor na segunda metade dos anos 80 .

O excedente de capital japonês encontrava, assim, um canal alternativo para sua aplicação no sistema econômico mundial, tanto no que se refere às aplicações produtivas (investimento externo direto), como aos investimentos estritamente de natureza financeira. O movimento líquido de capitais de curto prazo aumentou de US\$ 65 bilhões em 1985 para US\$ 132 em 1986. e ficou em torno deste valor nos dois anos seguintes. Somente em 1989 é que há uma queda do fluxo de internacional de capitais do Japão (saldo líquido de US\$ 89 bilhões). No período 1985-89, o Japão exportou capitais no valor aproximado de US\$ 500 bilhões.

A situação de capital barato no Japão na segunda metade dos anos 80 provocou diversos efeitos, que transcenderam o lado real da economia japonesa e suas relações com o resto do mundo. Os preços de ativos reais e financeiros entraram em uma trajetória de crescimento exponencial. Isto ocorreu no caso da terra, imóveis, ações e outros ativos. Para ilustrar, o índice Nikkei da bolsa de valores de Tóquio aumentou de 13.113 no final de 1985 para 30.000 no início de 1988. A valorização dos preços da terra também foi extraordinária, tendo crescido cerca de 200\% entre 1985 e 1990. Iniciou-se, assim, o conhecido processo de formação de "bolha" nos preços dos ativos reais e financeiros na economia japonesa como resultado do excesso de capital.

A apreciação do iene a partir de 1985 foi tão expressiva que, apesar dos esforços de aumento de produtividade e de redução dos custos por parte das empresas japonesas, a economia do Japão perdeu competitividade ao longo da segunda metade dos anos 80 . A participação do Japão no comércio mundial reduziu-se de $10,3 \%$ em 1986 para $8,5 \%$ em 1990 . Neste mesmo período, o acirramento da concorrência internacional, principalmente de outros países asiáticos, representou dificuldades crescentes para as exportações japonesas de produtos manufaturados. A participação do Japão no comércio mundial de produtos manufaturados caiu de 14,2\% em 1985 para 11,3\% em 1990 (GATT, 1992, p. 31).

Ademais, o movimento de expansão de investimentos na infra-estrutura econômica e social, na segunda metade dos anos 80 , foi perdendo fôlego 
como fonte de expansão da demanda agregada ao longo dos anos. Os anos 90 para a economia japonesa iniciaram-se, então, com a síndrome de excesso de capacidade de produção industrial, tendo em vista as dificuldades de expansão da demanda externa.

De fato, a demanda interna no Japão mostrou os primeiros sinais de estagnação no início dos anos 90 . $\mathrm{Na}$ arena internacional, a situação piorou com os efeitos negativos da recessão da economia dos Estados Unidos em 1990-91. Em 1991, a economia japonesa mantém sua taxa de crescimento do PIB de $3,8 \%$, que foi a média dos anos 80 . Todavia, em 1992, a economia japonesa entrou em uma evidente trajetória de crise econômica, marcada, entre outros fatores, pelo crescimento medíocre da produção e da renda.

A insuficiência de demanda agregada, tanto no mercado interno como no mercado externo, provocou excesso de capacidade produtiva e redução das taxas de lucro. A queda da taxa de investimento foi o resultado imediato - a taxa de formação bruta de capital fixo caiu continuamente entre 1991 e 1995, de 32,2\% em 1991 para 28,6\% em 1995 (United Nations, 1998, p. 129). No período 1992-94, o volume de investimentos no Japão caiu ano após ano (IMF, 1998, p. 145-147; United Nations, 1998, p. 129).

No início dos anos 90, a economia japonesa defrontou-se, ademais, com um processo crítico de endividamento generalizado, tendo em vista a política de capital barato da segunda metade dos anos 80 . Este processo acompanhou o crescimento da bolha de preços de ativos reais e financeiros. Ao mesmo tempo, os esforços de redução de custo por parte das empresas japonesas não foram suficientemente fortes para compensar a dramática apreciação do iene a partir de 1985. O custo unitário da mão-de-obra no Japão continuou crescendo a taxas relativamente altas até 1994 e é somente a partir de 1994 que este custo começa a ser reduzido.

A apreciação do iene entre 1990 e 1995 continuou a minar a competitividade internacional da economia japonesa - a taxa de câmbio média (iene/ dólar norte-americano) caiu de 145 em 1990 para 94 em 1995. O resultado foi a perda de competitividade internacional da economia japonesa e a menor contribuição do mercado externo como fonte de expansão da demanda agregada. A demanda doméstica mostrou os primeiros sinais de perda de dinamismo no início dos anos 90. Em 1992, o governo japonês apelou para aumentos extraordinários de gastos públicos - a saída keynesiana tradicional - para enfrentar o problema de insuficiência de demanda agregada.

$O$ estouro da bolha de preços de ativos no início da década de 90 agravou ainda mais a situação de insuficiência de demanda agregada. $\mathrm{O}$ "efeito riqueza negativo" provocou um comportamento de maior cautela por parte de consumidores e empresas japonesas. A trajetória de estagnação a 
partir de 1992 prolongou-se, até que em 1995 o governo japonês promoveu um afrouxamento fiscal e monetário, que interrompeu o processo recessivo. $O$ déficit fiscal do governo central foi de $4,1 \%$ em 1995 e $4,2 \%$ em 1996 . A política fiscal expansionista foi reforçada por uma política monetária também expansionista - a oferta monetária (M1) cresceu 13,1\% em 1995 e $9,7 \%$ em 1996, enquanto a taxa de juros de títulos públicos (overnight) reduziu-se de $2,1 \%$ em 1994 para 1,2\% em 1995, e 0,4\% em 1996. Como resultado, o PIB japonês cresceu 3,9\% em 1996.

A recuperação econômica do Japão mostrou-se insustentável em 1997 por meio da via keynesiana de expansão dos gastos públicos. A situação agravou-se com os primeiros sinais de crise na Tailândia em julho de 1997 crise esta que se estendeu pelo Sudeste Asiático ao longo de 1997 e 1998. Não resta dúvida de que o colapso das economias da Tailândia, Coréia do Sul, Indonésia e Malásia foram determinantes da crise da economia japonesa a partir de 1997 (BRENNER, 1998, p. 261).

A importância da Ásia para a economia japonesa pode ser vista no peso relativo dos mercados asiáticos para as exportações japonesas. Em 1996, 46\% das exportações japonesas eram para os países da Ásia (WTO, 1997, vol. 2, p. 150-151). As importações dos países asiáticos (excluindo China e Índia), que tinham crescido a uma taxa média anual de aproximadamente $20 \%$ no período $1993-95$, cresceram $6,8 \%$ em 1996 e tiveram quedas de 0,2\% em 1997 e de 3,5\% em 1998, segundo estimativas (IMF, 1998, p. 178). As desvalorizações das moedas de países como Coréia, Malásia, Tailândia e Indonésia - ancorados no dólar norte-americano - provocaram o acirramento ainda maior da concorrência internacional. As exportações japonesas tiveram uma queda em 1997, tendo em vista a contração dos mercados asiáticos.

Entretanto, a partir de 1995, iniciou-se um significativo processo de depreciação do iene, revertendo a tendência de 1985-95. A taxa de câmbio iene/dólar, que quase chegou a 80 em 1995, começou a subir e passou do valor médio de 94 em 1995 para 110 em 1996, 121 em 1997 e 145 em julho de 1998. Esta mudança de preços relativos entre 1995 e 1998 (depreciação cambial) foi um fator favorável no que diz respeito ao desempenho econômico japonês neste período.

Todavia, a perda de dinamismo da economia a partir, principalmente, de 1992 foi acompanhada pelo agravamento dos desequilíbrios no setor financeiro. Quando a bolha de preços de ativos estourou, o setor produtivo e as famílias encontraram-se endividadas. $\mathrm{O}$ resultado foi que os bancos e as instituições financeiras encontraram-se frente a portfólios de ativos desvalorizados. Segundo estimativas, os "títulos podres" representariam algo como 
$30 \%$ dō PIB japonês (The Economist, 26 de setembro de 1998). Os problemas do setor financeiro passaram a exigir um volume substancial de recursos públicos para a restruturação (por exemplo, via fusões), liquidação e o financiamento de operações de resgate de bancos e instituições financeiras no Japão.

Deve-se, ressaltar, entretanto, que os problemas da economia japonesa têm origem na insuficiência de demanda agregada provocada pelo elevado nível de desenvolvimento econômico e social do país. O excesso de capital no Japão - onde a taxa de poupança doméstica tem sido historicamente superior a $30 \%$ - provocou bolhas de preços de ativos reais e financeiros, que criaram os problemas graves para a economia japonesa. A fragilidade do sistema financeiro japonês resulta, assim, de um desequilíbrio sistêmico no lado real da economia.

As dificuldades crescentes de realização do capital na esfera produtiva ao longo dos anos 80 implicaram uma reorientação deste capital, principalmente, para a esfera financeira. O "capital barato" no Japão encontrou saídas no sistema econômico mundial, por meio do investimento externo direto e do investimento de portfólio. No mercado interno, os deslocamentos envolveram as bolhas de preços de ativos reais e financeiros. A explosão destas bolhas no final dos anos 80 e início dos anos 90 significou uma tensão para a economia japonesa. $O$ fenômeno da baixa rentabilidade de ativos comprados a preços extraordinariamente elevados agravou a situação financeira do país, principalmente, quando os "créditos podres" começaram a afetar a saúde dos bancos e instituições financeiras.

A desestabilização macroeconômica associada ao fraco desempenho acabou provocando tensões sociais e políticas, que se tornaram restrições adicionais para a solução dos problemas econômicos. Neste sentido, dentre as principais incertezas críticas próprias ao Japão cabe destaque para a insuficiência de demanda interna, a crise financeira e a instabilidade política no que diz respeito à hegemonia partidária no sistema parlamentarista japonês.

Nesta virada de século, o Japão defronta-se com um cenário mundial de franca desaceleração e um cenário doméstico de enormes dificuldades econômicas e políticas. A questão de grande relevância para a economia japonesa é que, apesar da relação exportação/PIB ser de aproximadamente $15 \%$, o setor industrial japonês - que se constitui no motor de crescimento econômico - tem uma significativa dependência com relação ao mercado internacional. Estas exportações absorvem cerca de metade da produção industrial japonesa. Esta dependência com relação ao mercado internacional significou uma extraordinária vulnerabilidade externa e, portanto, agrava ainda mais a trajetória de instabilidade e crise da economia japonesa. 


\section{0 impulso financeiro e o motor de arranque da economia norte-americana: locomotiva enferrujada do capitalismo no século XXI}

A taxa de crescimento de longo prazo da economia norte-americana reduziu-se de $4,0 \%$ no período $1960-73$ para $2,3 \%$ no período $1980-97$. Esta última taxa representa, na realidade, a taxa para a qual estão convergindo as principais economias capitalistas avançadas (Alemanha, Reino Unido, França e, também, Japão). Esta queda da taxa de crescimento do PIB norteamericano pode ser atribuída, por um lado, à desaceleração do crescimento da produtividade norte-americana (olhando pelo lado da oferta). No entanto, a explicação básica reside na própria perda de dinamismo da absorção interna em economias maduras (lado da demanda).

Os anos 90 foram marcados, na sua primeira fase, por um ciclo recessivo, que se iniciou em 1989 e durou até 1992, quando surgem os sinais de uma nova fase que chega até os dias de hoje, que é o atual ciclo expansionista. Ao longo dos anos 90, a taxa de crescimento da economia norteamericana foi superior a do Japão e a do conjunto dos países da União Européia. E mais, a partir de 1997, a taxa de crescimento econômico dos EUA tem sido maior do que o crescimento econômico mundial. Este é um fato que não é novo, tendo em vista os desempenhos nos anos 50 e 60, mas é um fato raro nestes últimos vinte e cinco anos. Neste sentido, o atual ciclo expansionista envolve uma certa singularidade, principalmente, no que se refere ao efeito locomotiva exercido pela economia norte-americana sobre a economia mundial.

Deve-se notar, no entanto, que o crescimento da economia norte-americana ao longo dos anos 90, que inclui um ciclo recessivo inicial em 1989-91 e um ciclo expansivo posterior (1992-1999) é menor do que o crescimento ao longo dos anos 80, que também inclui um ciclo recessivo em 1980-82 e um ciclo expansivo em 1983-88. De fato, o crescimento médio anual do PIB norte-americano foi de 2,7\% em 1980-89 e 2,2\% em 1990-99. Assim, a singularidade do atual ciclo expansionista da economia norte-americana, em termos do seu efeito locomotiva, deve ser qualificada no sentido da menor potência da locomotiva norte-americana atual comparativamente a do ciclo expansivo anterior.

No que se refere à natureza básica do atual ciclo de expansão da economia norte-americana, a diferença marcante entre a década de 80 e a década de 90 é que, na primeira, o crescimento deveu-se, principalmente, ao aumento do consumo privado e dos gastos públicos, enquanto, nos anos 90 , o crescimento deveu-se, sobretudo, ao consumo e ao investimento privado. 
Ainda como distinção marcante entre as duas últimas décadas, deve-se notar a queda da contribuição dos gastos públicos e o aumento dos investimentos nos anos 90. Assim, a taxa de crescimento anual do investimento, que tinha sido de 2,2\% em 1980-89 (inferior à taxa de crescimento do PIB), praticamente duplicou na década de 90 , tendo atingido $4,1 \%$, praticamente do dobro da taxa de crescimento do PIB.

As taxas médias de poupança e de investimento doméstico dos EUA, ao longo da década de 90 , são inferiores às suas taxas históricas. Este fato refere-se à taxa de poupança privada, e às taxas de investimento privado e público. A única exceção refere-se à taxa de poupança pública, que aumentou ao longo do último ciclo expansionista. A taxa de poupança total reduziu-se de uma média de $18 \%$ no período $1976-91$ para menos de $16 \%$ nos anos 90 . Esta redução da poupança total decorre da queda significativa da privada (de $17 \%$ para cerca de $15 \%$ ), enquanto a taxa média de poupança do setor público mantém-se na média de $1 \%$. Deve-se notar ainda que, nos últimos anos deste ciclo expansivo mais recente, a taxa de poupança privada teve uma queda e chegou a $14 \%$ (1997-98), enquanto a taxa de poupança pública aumentou para cerca de $3 \%$.

Ademais, cabe assinalar que o componente da taxa de poupança privada correspondente às empresas não se alterou significativamente ao longo do ciclo expansivo. A redução da poupança privada deve-se à queda extraordinária da poupança individual (dos domicílios). Para ilustrar, em 1992 a taxa de poupança privada era de $15,6 \%$, sendo que a poupança das empresas era de $11,0 \%$ e a dos domicílios de $4,6 \%$. Em 1997, a taxa de poupança privada caiu para $14,3 \%$, sendo que a taxa de poupança das empresas foi de $11,5 \%$ e a dos domicílios reduziu-se para $2,8 \%$ (BIS, 1998, p. 19).

A taxa de investimento total da economia norte-americana tem mostrado uma tendência de crescimento ao longo deste último ciclo e chega a $18,7 \%$ em 1998. Esta taxa é, entretanto, inferior às taxas médias de investimento nos anos 70 e 80 , que eram da ordem de $20 \%$. Ademais, o crescimento da taxa de investimento total decorre do crescimento da taxa de investimento privado, que tem apresentado uma tendência de crescimento. A taxa de investimento privado aumentou de $12,7 \%$ no início do ciclo em 1992 para $15,9 \%$ em 1998. Por outro lado, a taxa de investimento público tem mostrado uma tendência de queda (ainda que pouco acentuada). A taxa de investimento público reduziu-se de 3,3\% em 1992 para 2,8\% em 1998. Esta queda reflete o ajuste fiscal do governo dos EUA, com a redução dos gastos e aumento das receitas.

Ao longo dos anos 90, a economia norte-americana apresenta uma nítida e forte tendência de redução do desequilíbrio das contas públicas. $\mathrm{O}$ 
saldo fiscal do governo geral passou de um déficit de 4,4\% do PIB em 1992 para superávit de $0,1 \%$ do PIB em 1998 . O esforço fiscal do governo central não foi menos expressivo na medida em que o déficit reduziu-se de $6,3 \%$ do PIB em 1992 (início do ciclo de expansão) para 2,8\% do PIB em 1998. Assim, em pleno processo de aceleração da economia, o governo dos EUA logrou reduzir significativamente o desequilíbrio das contas públicas.

As contas públicas norte-americanas se beneficiaram de um aumento de receita. Neste sentido, deve-se notar o aumento da receita tributária (imposto de renda das pessoas físicas e pessoas jurídicas) decorrente da elevação dos preços das ações. A venda de ações a preços mais elevados caracteriza uma renda e, portanto, um aumento da arrecadação do imposto sobre a renda.

No que se refere à redução da poupança privada, deve-se levar em conta o impacto do aumento de riqueza sobre o consumo. Nos EUA, $57 \%$ da riqueza privada (pessoas físicas) consiste de ativos financeiros e $43 \%$ da população adulta tem investimentos no mercado de ações. As ações representaram 28\% da riqueza financeira dos domicílios em 1997 (BIS, 1998, p. 21). O aumento do preço real das ações tem um efeito em termos de aumento de riqueza e, portanto, de aumento do consumo privado e redução da poupança das famílias. As estimativas mais recentes indicam que o aumento real dos preços das ações provocou o crescimento do consumo de $0,43 \% \mathrm{em}$ $1995,0,51 \%$ em 1996 e $0,84 \%$ em 1997 . Este impacto representou aproximadamente um quarto do crescimento total do consumo em 1997.

Neste sentido, a valorização financeira tem sido uma importante fonte de expansão da demanda agregada norte-americana ao provocar o aumento do consumo privado nos últimos anos do século XX. A questão central reside em saber até quando deve durar este processo de valorização financeira. Não é por outra razão que alguns analistas argumentam que há "um cheiro de anos 30 no ar".

\section{Conclusão}

As dificuldades atuais do sistema capitalista recolocam com grande ênfase o papel a ser desempenhado pelas principais "locomotivas" do sistema. A economia japonesa continua sofrendo as conseqüências do problema da insuficiência de demanda agregada, que caracteriza as economias capitalistas maduras. A situação japonesa agravou-se ainda mais nos últimos anos com a crise financeira e bancária que atingiu o país. O crescimento modesto das economias européias, por seu turno, parece também limitado por políticas macroeconômicas restritivas orientadas para a satisfação dos critérios de 
convergência de Maastricht, que acompanham o avanço da integração econômica regional e a integração monetária, em particular.

A economia dos Estados Unidos, por seu turno, representa $20 \%$ do valor da produção mundial (estimado em US\$ 30 trilhões) e, portanto, é candidato natural a locomotiva do sistema econômico mundial. A partir de 1992 a economia norte-americana entrou em uma trajetória de expansão. No entanto, após sete anos de crescimento elevado, pelos padrões históricos norte-americanos, a economia dos EUA pode estar chegando ao final do seu ciclo de expansão.

Alguns fatos importantes poderão ser determinantes da trajetória da economia mundial na virada do século. A situação japonesa continua altamente instável, de tal forma que, entre planos e medidas, a economia do Japão continua em uma trajetória de recessão e, até mesmo, com sintomas de depressão, que são restrições à acumulação na Ásia. Nas economias emergentes da Ásia, deverá se verificar uma extraordinária heterogeneidade de trajetórias de enfrentamento da crise econômica. Alguns destes países poderão se afundar ainda mais em situações de crise, que transcendem a esfera econômica e financeira, e atingem as dimensões social, política e institucional. No caso da Europa Central e Oriental, as incertezas não são menos importantes, com trajetórias também heterogêneas. $O$ risco de situações de crises graves na região dos Balcãs continua presente na agenda internacional. A Rússia, por seu turno, continua num processo de crise sistêmica e, portanto, as trajetórias futuras parecem todas erráticas. $\mathrm{Na}$ América Latina é provável que economias-chaves da região, como o Brasil, se afundem em profundos processos de instabilidade e crise, com implicações importantes nas esferas econômica, social, política e institucional.

Ao fim e ao cabo, a percepção é de que a economia mundial, em geral, e a norte-americana, em particular, estão numa situação de encruzilhada, de tal forma que as trajetórias no século XXI deverão ser, na melhor das hipóteses, difíceis.

Ao longo do século XX o capitalismo mostrou-se um sistema altamente instável. Ademais, os sinais de senilidade do sistema tornaram-se cada vez mais evidentes na medida em que se aproximava a virada do século XX para o século XXI. Para enfrentar a trajetória marcadamente cíclica do sistema capitalista um conjunto de remédios têm sido aplicados com resultado variável ao longo de mais de um século. Estes "velhos remédios" têm sido usados de forma recorrente e deverão se constituir na base de tratamento do sistema no século XXI.

As intervenções pontuais assentadas nos gastos públicos, bem como o progresso técnico, têm se mostrado pouco eficazes para reduzir a instabili- 
dade e a exclusão social. A internacionalização da produção, via globalização, pode estar entrando em um fase de "retornos decrescentes" na medida em que todos os países procuram o mercado internacional. As restrições à saída política (distribuição de riqueza e renda) são crescentes quando os social-democratas parecem liberais maquiados pelos cosméticos da Terceira Via, e a esquerda socialista se sente acuada com a ruptura do bloco soviético. O remédio tão antigo quanto potente do capitalismo - a guerra - pode ter suas dosagens aumentadas no futuro, se os outros remédios continuarem ineficazes ou restritos.

O New Deal terminou, sem reverter a crise econômica que eclodiu em 1929. No final dos anos 30 entrou em ação um poderoso mecanismo de resgate do sistema econômico dos EUA: a Segunda Guerra Mundial. No período "dourado" que vai até o início dos anos 70, a Guerra Fria foi um potente combustível para a máquina de acumulação capitalista. $\mathrm{O}$ ciclo expansivo dos anos 80 (1983-89) foi determinado, em grande medida, pelos elevados gastos com o programa bélico "guerra nas estrelas". A guerra, generalizada ou localizada, aberta ou "fria", é um recurso tão eficaz (para a expansão da demanda agregada) quanto terrificante. Não é por outra razão que o século $\mathrm{XX}$ foi o mais sangrento de toda a história da humanidade.

Os bombardeios sobre a Sérvia, pelas forças militares dos países desenvolvidos sob a liderança dos EUA, "podem mesmo transformar uma guerra fria potencial em uma guerra quente se a Rússia entrar no conflito ao lado da Sérvia, possivelmente provocando um conflito mais amplo na Europa ou mesmo uma 'terceira guerra mundial'." (The Economist, 17 de abril de 199 , p. 19). No final do século XX os conflitos bélicos nos Balcãs podem estar antecipando o início do século XXI.

\section{Referências bibliográficas}

ARRIGHI, G. (1996), O Longo Século Vinte, Rio de Janeiro, Ed. Contraponto. BIS (1998), Annual Report, 1998, Basle, Bank for International Settlements. BRENNER, R. (1998), The Economics of Global Turbulence. A Special Report on the World Economy, New Left Review, No 229.

GATT (1992), International Trade 91-92, Genebra, General Agreement on Tariffs and Trade.

GONÇALVES, R. (1999), Globalização e Desnacionalização, Rio de Janeiro, Ed. Paz e Terra.

HOBSBAWM, E. (1997), A Era dos Extremos, São Paulo, Cia. das Letras.

IMF (1998), World Economic Outlook, Washington DC, International Monetary Fund, maio. 
LE MONDE (1996), Jäpon, la fin de l'exceptiön, Paris, Le Monde Dossiers \& Documents, $\mathrm{N}^{\circ} 241$, março.

MADDISON, A. (1991), Dynamic Forces in Capitalist Development. A Long-run Comparative View, Oxford University Press

UNCTAD (1995), Trade and Development Report, 1995, Genebra, United Nations Conference on Trade and Development.

United Nations (1998), World Economic and Social Survey, 1998, New York, United Nations.

VAN DER WEE, H. (1984), Histoire Économique Mondiale, 1945-1990, Paris, Academia Duculot.

WTO (1997), Annual Report 1997, Genebra, World Trade Organization. 